\title{
Cyclone promotes rapid colonisation of benthic diatoms in the Great Barrier Reef
}

Received: 23 May 2007 / Accepted: 18 June 2007/ Published online: 13 July 2007

(C) Springer-Verlag 2007

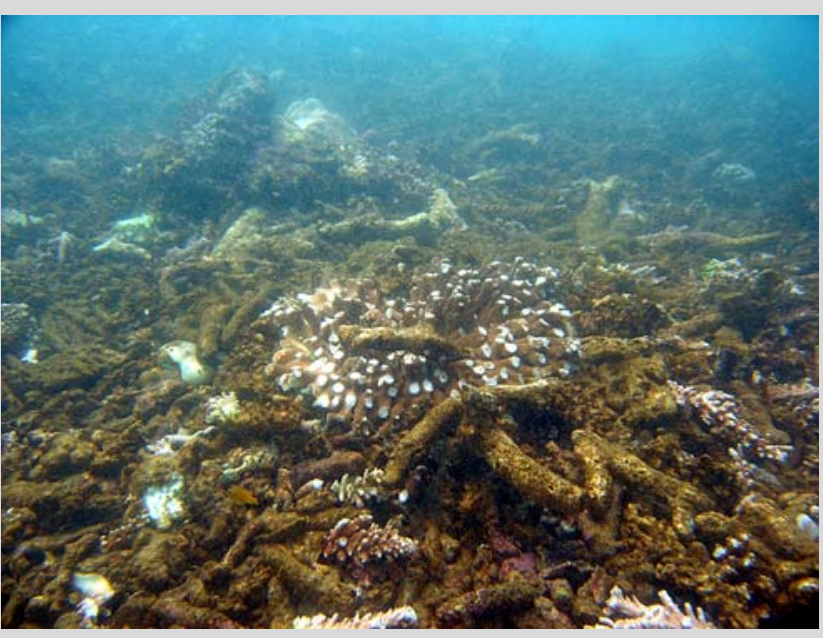

Fig. 1 Coral breakage caused by Cyclone Larry (Acropora sp. $5 \mathrm{~m}$ depth), followed by colonization of recently exposed substrate by benthic diatoms, giving the reef a yellowish coloration
Tropical Cyclone Larry (TCL) crossed the Great Barrier Reef (GBR) on 20 March 2006, close to the town of Innisfail $\left(18^{\circ} 30^{\prime} \mathrm{S}, 146^{\circ} 00^{\prime} \mathrm{E}\right)$. TCL was a severe Category 5 cyclone, which generated wind gusts of up to $240 / 290 \mathrm{~km} \mathrm{~h}^{-1}$ and sustained winds of up to $170 / 215 \mathrm{~km} \mathrm{~h}^{-1}$. Three days after the cyclone, surveys of several offshore and inshore reefs revealed extensive damage, including breakage and overturning of corals, dislodgement and tearing of soft corals and sponges, exfoliation of reef matrix, transport of sand and dislodgement of seaweeds. The benthic algal community responded rapidly to the cyclone disturbance. Newly available substrates were immediately colonised by an extensive bloom of benthic, pennate diatoms, giving the reef a yellowish coloration (Fig. 1). The bloom apparently resulted from the increase in substrate available for colonisation, but may also have been promoted by nutrient increases, either from run-off (on inshore reefs) or by storm-disturbed sediments (e.g., Russ and McCook 1999). There have been few documented examples of blooms of benthic diatoms after cyclone disturbances, although their planktonic counterparts (Delesalle et al. 1993) and some green benthic macroalgae (Littler and Littler 1999) are known to bloom after storms.

Acknowledgments The authors extend their thanks to the crew of the S.V. Pelican 1 for field support and to the Pew Program in Marine Conservation for support to GDP.

\section{References}

Delesalle B, Pichon M, Frankignoulle M, Gattuso JP (1993) Effects of a cyclone on coral reef phytoplankton biomass, primary production and composition (Moorea Island, French Polynesia). J Plankton Res 15:1413-1423

Littler MM, Littler DS (1999) Disturbances due to cyclone Gavin parallel those caused by a ship grounding. Coral Reefs $18: 146$ Russ GR, McCook LJ (1999) Potential effects of a cyclone on benthic algal production and yield to grazers on coral reefs across the central Great Barrier Reef. J Exp Mar Biol Ecol 235:237-254

G. Diaz-Pulido (ه) • L. J. McCook

ARC Centre of Excellence for Coral Reef Studies, University of Queensland, St Lucia 4072, QLD, Australia

e-mail: g.diazpulido@uq.edu.au

G. Diaz-Pulido

Centre for Marine Studies, University of Queensland, St Lucia 4072, QLD, Australia

G. Diaz-Pulido

Universidad del Magdalena, Santa Marta, Colombia

A. Chin · J. Davidson · L. J. McCook

Research and Monitoring Coordination, Great Barrier Reef Marine Park Authority, PO Box 1379, Townsville, QLD 4810, Australia

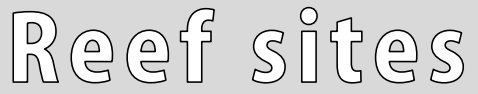

Coral Reefs (2007) 26:787

DOI $10.1007 / \mathrm{s} 00338-007-0269-\mathrm{z}$ 